\title{
The Slope of the Credit Yield Curve for Speculative-Grade Issuers
}

\author{
by \\ Jean Helwege \\ and \\ Christopher M. Turner*
}

This version: June 1998 


\title{
The Slope of the Credit Yield Curve for Speculative-Grade Issuers
}

\author{
ABSTRACT \\ Many theoretical bond pricing models predict that the credit yield curve facing risky bond \\ issuers is downward sloping. Previous empirical research (Sarig and Warga (1989) and Fons \\ (1994)) supports these models. Our study examines sets of bonds issued by the same firm with \\ equal priority in the liability structure, but with different maturities, thus holding credit quality \\ constant. We find, counter to prior research, that risky bonds typically have upward-sloping \\ credit yield curves. Moreover, when we combine our matched sets of bonds (no longer \\ controlling credit quality), the estimated slope is negative, indicating a sample selection bias \\ problem associated with maturity.
}




\section{The Slope of the Credit Yield Curve for Speculative-Grade Issuers}

Using option analysis, Merton (1974) shows that corporate bond spreads can either increase or decrease with maturity, depending on the risk of the firm: high-grade corporate issuers face upward-sloping credit yield curves while speculative-grade firms' credit yield curves are downward sloping or hump-shaped (i.e., mostly downward sloping). More recent theoretical research (e.g., Jarrow, Lando, and Turnbull (1997) and Longstaff and Schwartz (1995)) tends to predict similar credit yield curves. Sarig and Warga (1989) and Fons (1994) find empirical evidence supporting these models.

While market practitioners tend to agree with academics that the risk term structure is upward-sloping for high-quality credits, typically practitioners do not view the slope of the curve facing high-yield issuers as negative. ${ }^{1}$ Our investigation provides some empirical support for the practitioners' view of the world: contrary to many bond pricing models' predictions, the credit yield curve for most speculative-grade firms appears upward-sloping.

Our results differ from those of Sarig and Warga (1989) and Fons (1994) because of sample selection bias associated with maturity choice. That is, among firms with the same credit rating the safer ones tend to issue longer-dated bonds. This causes the average spread to decline with maturity, even though for an individual firm the spread typically might increase with maturity. In our study, we avoid this problem by examining sets of bonds on a given day that are issued by the same firm but differ in maturity. We analyze two databases: new offerings of bonds from Securities Data Corp. (SDC), because prices for new issues are typically more reliable than 
those found for infrequently traded outstanding bonds; and secondary bond prices of firms with more than one bond outstanding in the Lehman Brothers Fixed Income Database. The latter source is added to allay doubts about the type of firms choosing to issue multiple bonds on a single day; further, it increases observations on noncallable bonds.

In the next section we discuss the theoretical and empirical literature. Section II describes the new issues data and our selection criteria. Section III reports our findings in the SDC database. Section IV shows the effects of credit quality on regression estimates. Section V extends the analysis to secondary bond price data. Section VI reports data on the risk of the bonds in the market relative to those evaluated in the models. Section VII is the conclusion.

\section{Theory and Evidence}

Merton's (1974) seminal work on the valuation of corporate bonds uses option pricing theory to value a zero-coupon corporate bond with a face value of $\mathrm{B}$, a term to maturity $\mathrm{T}$, issued by a firm with value V. Merton notes that this bond can be valued as the difference between $\mathrm{V}$ and the value of the firm's equity, measured by the Black-Scholes formula. The price of the bond can be expressed as a function of $\mathrm{T}$ and $\mathrm{d}$, the "quasi-debt ratio" of the firm $\left(\mathrm{Be}^{-\mathrm{r \tau}} / \mathrm{V}\right)$. (Note that $\mathrm{d}$ is typically greater than the ratio of the firm's market leverage and typically lower than the firm's book debt-to-capitalization ratio.)

Rewriting the price as a premium over the riskfree rate, Merton shows the premium increases with leverage (d) and the volatility of the firm's earnings, but can either increase or decrease with maturity. For values of $d$ greater than or equal to one, the premium over the riskfree rate decreases with maturity. For lower values of $d$, the credit yield curve is either 
strictly upward sloping or hump-shaped (see Pitts and Selby (1983) for graphs of the credit yield curve).

The intuition behind these results is as follows: Bond values depend on the probability of default, which varies with the value of the firm. Among the highest quality bonds, the probability of default is very small at issuance so that there is little chance of an improvement in the probability of repayment, regardless of how high firm value rises. In contrast, the possibility of substantial downward movement in credit quality is fairly high, given enough time. Thus, the credit yield curve is upward-sloping for high-grade firms. Speculative-grade bonds, however, being very risky at issuance, have room to improve with age, and less potential to worsen. The longer the maturity of the bond, the more likely that the value of the firm will rise substantially. If the bond at issuance has nowhere to go but up over time, the credit yield curve is strictly downward sloping. For firms that are a bit less risky, the potential to deteriorate in quality in the short term dominates, but is offset by the upside potential in the longer term, leading to a humpshaped credit yield curve.

Merton's analysis involves some very strict assumptions that have been relaxed in more recent work. Jarrow, Lando, and Turnbull (1997) present a model for zero-coupon corporate bonds in which the probability of default follows a Markov process. They find, for some parameter values, credit yield curves similar to those in Merton. For example, most investmentgrade bonds have upward-sloping risk term structures, while BB and B-rated bonds (the safest of the speculative-grade bonds) face hump-shaped credit yield curves, and CCC-rated firms' curves are strictly downward sloping. For the portion of the term structure typically observed in new issues databases (maturities of five or more years), the B curve predicted by Jarrow et al. is 
downward sloping, and mostly so for the BB curve.

Longstaff and Schwartz (1995) present a model for coupon bonds in which firm value is correlated with the riskfree rate. In the presentation of their model, the credit yield curve may be upward-sloping or hump-shaped, but not strictly declining. The peak spread for the hump-shaped curve occurs at the third year, however, so that most of the credit yield curve facing very risky issuers is negatively sloped. Given the appropriate parameter values, this model could also generate a downward-sloping credit yield curve for speculative-grade firms. For example, Wei and Guo (1997) apply the Longstaff and Schwartz model to Eurodollar spreads in 1992 and show that the credit term structure is mostly downward-sloping for the values of $\mathrm{X}$ observed in their data. $^{2}$

Fons (1994) provides a simple numerical model of bond pricing in which the value of the bond depends on the probability of default each period and the recovery rate if default occurs. Based on Moody's default data by rating (which show a strictly declining probability of default for B-rated issuers) and Moody's data on average recovery values, the model predicts a downwardsloping credit yield curve for the lower-tier speculative-grade firms.

The empirical evidence on the shape of the credit risk term structure largely substantiates the theoretical predictions. Sarig and Warga (1989) analyze secondary prices (trader quotes) of zero-coupon corporate bonds, a fairly unusual type of bond, over the period 1985-87. The sample includes both callable and noncallable bonds, but excludes bonds that are likely to be called. They calculate average spreads by rating for maturity categories with two-year intervals. For the B and C-rated bonds, Sarig and Warga find a strictly negatively-sloped risk structure. The evidence on BB-rated bonds is similar, albeit slightly weaker. 
Fons (1994) analyzes all corporate bonds (mostly coupon bonds) rated by Moody's Investors Service on a particular day and estimates a cross-sectional regression of spreads on maturity. He finds a significantly negative coefficient for B-rated issuers and an essentially zero coefficient for Ba-rated (BB-rated) issuers, indicating a negative or flat credit yield curve for speculative-grade firms.

We argue that these empirical studies do not control correctly for credit quality. While ratings measure risk broadly, they do not reflect fully the differences in credit quality across firms - the variance of credit quality within a rating category is great for firms in the high-yield universe. This statistical error in ratings can lead to a sample selection bias in the estimated slope of the credit yield curve because of the endogeneity of bond maturity (see Ravid (1996) for a survey on maturity choice). When the more creditworthy firms in a given rating category are most likely to issue long-term bonds, the estimated credit yield curve for that rating category will be biased downward.

\section{Sets of Bonds Issued by the Same Company on the Same Day}

We reexamine the credit yield curves of risky bonds, holding the credit quality of the bonds constant by analyzing multiple bonds of the same company that are equal in the priority structure. To examine multiple bonds issued by the same company that are identical in every respect except maturity, we create a sample of bond sets issued on the same day by the same company. First, we identify all non-investment-grade bond offerings listed in the Securities Data Company (SDC) database from 1977 to 1994, restricting the sample to straight public bonds sold in the U.S. 
Of these 2186 bonds, we identify 433 bonds that were sold on the same day as other bonds of the same company. Thus, multiple bond offerings constitute about a fifth of all highyield bond offerings.

Table I shows the selection process applied to these 433 bonds to make sure the matches are appropriate for examining the shape of the credit term structure. First, we eliminate 16 bonds that do not differ by maturity. We next check that the bond matches have a speculative-grade rating from either Moody's or S\&P. If none of the bonds in the matched set has a rating, the set is dropped from the sample because we cannot be sure these issues are really speculative-grade. We do not drop matches, however, where at least one bond in the set has a rating. We delete 32 sets (comprising 90 bonds) that have no rating information, but keep a handful of matched bonds for which limited ratings information is available.

Most of the remaining 140 instances of 326 matched bonds are deleted from the sample because they do not have identical credit risk -- that is, most of the matches involve bonds of differing seniority. Typically, the longer maturity bond is lower in the capital structure, meaning it is associated with a higher risk premium. Thus, the spreads on the junior, longer-term bonds reflect both a higher risk premium and movement along the credit yield curve, and the two cannot be differentiated. We eliminate 67 cases (145 bonds) because of differences in seniority.

We allow unusual coupon bonds in the sample as long as every bond in the set has the same type of coupon. We exclude six cases of matched sets that have only have one zero-coupon bond or only one reset-coupon bond. Another three cases have no spread data (six bonds). For bonds with spread data, the spread is calculated by comparing yields to the nearest on-the-run Treasury security. These data are provided by SDC. These price data are quite accurate because 
they are reported to the Securities and Exchange Commission by the company after issuance. Moreover, most high-yield bonds are sold at par, in which case the offering yield is equal to the bond's coupon.

After deletions, our sample includes 64 offerings of 163 bonds. Bonds rated no lower than BB- by either S\&P or Moody's (Ba3) - comprise 42 of the offerings, while the remaining 22 cases have a rating of $\mathrm{B}+$ or lower (only one set of bonds a rating below $\mathrm{B}-$ ).

We allow the bonds to have differing call protection because the differences in call values are likely to be small. Call options themselves do not add substantially to the yield on the bond Crabbe (1991) estimates that call options contribute nine basis points to the spread on average. Crabbe's estimates are based solely on investment-grade bonds, which, as Crabbe and Helwege (1994) show, typically have more valuable options than those on speculative-grade bonds. Thus, the differences in call option values analyzed in this sample are unlikely to increase spreads much more than ten basis points when maturity rises. Nevertheless, we conduct separate analyses for the callable and noncallable bonds in the SDC database. An additional reason to include callable bonds is that the Sarig and Warga (1989) sample does not completely exclude them, nor does Fons (1994) exclude callable bonds. ${ }^{3}$ Note that the call option is not in the money for any of the bonds at issuance for two reasons: first, call protection typically will not expire for at least three years; and, second, the first call price is at a substantial premium over par (most of the bondss are issued at par).

\section{The Term Structure of Credit Spreads at Issuance}


Table II shows how the spread over Treasury changes as the maturity of the bond increases for a given company. The table shows outcomes by rating and by the type of call features in the set. Most of the matched sets are pairs (44 cases, 88 bonds), for which the term structure information is simple: the spread goes up, goes down, or it remains flat. For the triplets and quadruplets, spreads can go down for part of the term structure and up for other parts.

The matched sets show that the term structure of credit risk is positively sloped for both BB and B bonds. Most of the outcomes shown in Table II are purely upward-sloping: The spread rises with maturity in $31 \mathrm{BB}-$ rated sets and in $18 \mathrm{~B}$-rated sets. The fraction of matches that are strictly upward-sloping ranges from 61 percent to 93 percent for the different subsamples; for the entire sample, 77 percent of the matches reveal a strict increase in the spread as the maturity lengthens. In contrast, only six pairs are downward sloping or flat and no triplets are strictly downward sloping. Indeed, more sets had partly upward and partly downward slopes than strict downward slopes.

The bonds that are noncallable for life provide the most reliable information in the sample, and these also point to an upward-sloping credit curve. Among these sets, 14 have strictly upward-sloping credit curves while only five cases show a declining credit risk curve. While this fraction of perfectly positively sloped curves is smaller than the sample average, it is still very high. The fraction rises to 63 percent when all the noncallable sets are considered (that is, when the one noncallable B-rated set is included too).

We can further test the shape of the credit curve by applying $t$-tests and rank tests to the matches. These tests are detailed in Table III. The two-tailed $t$-test tests whether the average change in the spread is significantly different from zero. The signed rank test is nonparametric - it 
tests whether the spread rises or falls as maturity lengthens, giving higher weight to observations with large differences in spreads.

Each test is applied to matched pairs. Some of our data are triplets and quadruplets, so we use them by counting each point-to-point change in the spread as a pair. This means that a triplet supplies two pairs to the test (first datapoint to middle datapoint, and middle to endpoint) and a quadruplet counts as three pairs. Of the nine triplets that have positive slopes for part of the curve and negative slopes for other parts, six show an increase from the first spread to the last. ${ }^{4}$

The results of the $t$-test show that the credit risk curve is significantly positively sloped for both $\mathrm{BB}$ and $\mathrm{B}$ bonds. The average increase in spread is 14 basis points for the noncall life bonds, and 18 to 32 basis points among the sets with callable bonds.

Note that we do not hold constant the difference in maturity between pairs in the tests. Maturity increases by as little as a fraction of a year and by as much as 20 years in this sample. While moving out 20 years on the credit risk curve would likely sharply change the spread, moving out a year should have little impact; the $t$-test, however, makes no distinction. This should result in a much higher standard error of the mean, substantially increasing the probability of accepting the null hypothesis that the mean spread change is zero. We easily reject the null hypothesis despite the low power this conservative specification induces in our test.

The signed rank tests also indicate that the credit curve facing high-yield issuers is positively sloped. All five of the tests reject the null hypothesis that there is no difference in the spread as maturity increases: All the $Z$-scores are significantly positive and the small-sample signed rank test for the BB-rated all callable group also shows a significantly positive slope. 


\section{Comparison to Results Using Pooled Bonds}

Next, we consider whether firms that issue multiple bonds on a given day constitute a nonrandom sample of bond issuers. Moreover, it is possible that new issues themselves are not representative of corporate bonds. If the difference between our results and those of previous studies is due to the method of analysis, then the bias induced by including longer term bonds issued by safer firms should be found in our sample as well. If we estimate the regressions of spreads on maturity in our sample of matched bonds pooled together without holding constant issuer quality, we should find results similar to those of earlier studies.

Table IV shows estimations of regressions of yield spreads on bond maturity. Panel A estimates a regression of all new issues to determine whether the primary market spreads are consistent with the secondary market spreads used in previous research. Panels B and C are estimates from the sample of matched bonds. In addition, each sample is further restricted to include only bonds with maturities of 20 years or less, to make them more comparable to the sample used in Fons (1994). We present estimates for whole letter rating categories to make the results comparable to those in previous studies, but include estimates with modified ratings as well.

Panel A shows that the slope coefficient for the sample of all newly issued BB-rated bonds is significantly negative, consistent with the findings of Sarig and Warga (1989) and Fons (1994) that are based on secondary market prices. Likewise, the slope coefficient for the sample of newly issued bonds rated B or lower is also significantly negative. Restricting the samples to newly issued bonds with maturities of 20 years or less, the slope coefficients are not as negative, and in the case of the $\mathrm{BB}$ or higher rated bonds, turn significantly positive. Thus, new issues also 
tend to show negatively sloped credit yield curves.

Panel B of Table IV shows similar results for the sample of matched bonds. When these bonds are pooled together and the spread regressed on maturity, the slope coefficients of BB and B-rated bonds are negative. Although the coefficients are only significantly different from zero in one of the four regressions, the coefficients are similar in magnitude to those estimated for all newly issued bonds shown in the top panel of Table IV, indicating that matched bonds are not an unusual type of bond issuance.

The lack of credit quality controls in these regressions suggest that researchers should avoid whole letter rating categories and estimate regressions using the modified categories, as in Panel C. In all but the highest rating class, however, the coefficients still tend toward the negative even when the sample is analyzed by modified rating categories.

\section{Sets of Outstanding Bonds of the Same Company}

Our most reliable data source among the issuance data are the credit curves of noncallable bonds, but this sample of SDC bonds is small. To supplement this analysis we also examine sets of noncallable bonds that are outstanding obligations of the same company using data from the Lehman Brothers Fixed Income Database, which is based on Lehman Brothers' trader quotes at month end (see Warga (1997)). The secondary price database also has the advantage that there are no doubts about the pricing of debt for companies that issue two bonds on the same day because the bonds in this sample could have been issued at any point in time.

We examine all high-yield bonds for which trader quotes were available during the period January 1991-March 1995. We cross-checked the descriptive information about the bonds with 
the data in the SDC database to make sure that only maturity differed among the sets of bonds. Spreads are calculated off the interpolated yield curve, as few of the bonds have maturities comparable to those of the on-the-run Treasuries.

The Lehman Brothers Fixed Income Database can have many observations of the credit yield curve for a given firm, depending on how often the bonds trade. If we count each month a set of bonds trades in the database, some firms will be given higher weights than others. To give equal weights, we initially use only one observation per bond, choosing the month in the sample with the most trades of B-rated bonds. If a set of bonds did not trade that month, we take the closest month in which the bonds trade. Table V shows the credit yield curves observed in December 1993 or nearby. Among the firms with mixed results, we consider the yield curve to be mostly upward-sloping if the majority of the slope increases are positive and the endpoint to endpoint is upward-sloping.

The results based on these secondary bond prices are similar to those reported for the SDC data. The majority of the firms face yield curves that are strictly or mostly upward sloping. Moreover, the cases that were not upward sloping were not necessarily downward sloping or hump-shaped as the theory predicts (e.g., the BB curve that was down, down and then up). The mixed cases may indicate noise in the spreads, reflecting either inaccurate bond prices or inappropriate benchmarks.

Table VI shows significance tests for these results. The mean difference between the spreads for the BB and B bonds is positive, but not significantly so. The median difference is positive for the BB bonds, however. A Wilcoxon signed rank test is significantly positive for the BB bond, but not significantly so for the B bonds. The lower-rated bonds include Midlantic 
Bank's bonds, however, which were trading at distressed levels. If investors expected the bond to go into default, then they would expect all debts to accelerate, and all the firm's bonds would trade flat with the same expected maturity (the length of the bankruptcy or restructuring period). Calculating a yield curve for these bonds would induce a positive spread curve, when in fact there is no curve at all. ${ }^{5}$ Without Midlantic in the sample, the signed rank test will be significantly positive.

Using all of the observations in the Lehman Brothers Fixed Income Database, rather than just one month's observations, leads to similar evidence on the slope of the credit yield curve. As shown in Table VII, more than two-thirds of the credit yield curves slope upwards. And, as seen in Panel A, both the higher and lower rated bonds show a strong tendency toward upward-sloping credit curves. Moreover, as seen in Panel B, the instances of downward-sloping curves are more often observed when the Treasury curve is steeply sloped, suggesting that mismeasurement of the spread over linear interpolated Treasuries causes spurious downward slopes (when the Treasury curve is steep, the chances are greater that the riskfree rate used to calculate spreads has not been correctly measured).

\section{Evaluating the risk of risky corporate bonds}

Our results indicate that most speculative-grade bond issuers do not face downwardsloping credit yield curves. A simple explanation for the discrepancy between predicted and actual yield curves is the parameterization of the corporate bond pricing models. The downwardsloping credit yield curve occurs in the models because the equity-like optionality of the bond eventually dominates the pricing. If the actual corporate bond market includes few bonds with 
such upside potential, the observed yield curve will not be downward-sloping.

For example, the quasi-leverage parameter, $\mathrm{d}$, in the Merton model must be one or larger for the slope of the credit yield curve to be negative. If the market value of the debt is not very different from the book value (a standard assumption in corporate finance) and the face value of the debt is equal to its book value (true except for discount bonds), then the quasi-leverage ratio is bounded from below by market leverage ratios and above by book leverage ratios. Data from Standard \& Poor's on median book values of debt-to-capitalization ratios indicate that firms with leverage over one are not typical speculative-grade firms. For BB issuers, the median book leverage from 1992 to 1994 is 54.7 percent and market leverage is even lower at 45.7 percent. The respective numbers for the B-rated firms are 65.9 percent and 60.7 percent, leverage ratios that are well below one, the level required for Merton's slope to be negative. Moreover, the upper quartile of the book leverage ratio for B issuers is just over 80 percent. Standard \& Poor's do not report financial ratios for $\mathrm{CCC}$ bonds, because they are too small a portion of the corporate bond universe, but even these bonds may not have a quasi-leverage close to one. Perhaps such highly leveraged firms never issue in the public bond market at all, instead relying on private placements or bank loans for debt financing.

Another possible explanation for the results in our sample is that these bonds, while speculative-grade, may not be sufficiently risky on average to exhibit a downward-sloping curve. Rather, the minority of firms that do have negatively-sloped credit yield curves in the sample are those which are very highly levered. To examine this issue, we combine both the SDC and the Fixed Income databases and identify firms that have strictly upward-sloping curves and firms with strictly downward-sloping curves. Then we calculate market and book leverage ratios using 
Compustat and CRSP data to determine whether leverage ratios are higher among the latter group. We exclude banks and firms without Compustat data, and find that the average market leverage for firms with negative slopes, 16.6 percent, is not significantly different from that of the firms with postive slopes (17.7 percent). Likewise, book leverage is lower for the seven firms with downward-sloping credit yield curves, 38.9 percent, than for the 26 firms with strictly postiive credit yield curves, 59.7 percent. Hence, we cannot attribute the negative slopes in this sample to a subsample of very risky firms.

The Jarrow, Lando, and Turnbull (1997) model predicts a downward-sloping credit curve for $\mathrm{BB}$ and $\mathrm{B}$ firms, without any requirements concerning leverage ratios. This suggests that the negative slope of the credit may be driven by other features of the model, such as the volatility of the value of the firm's assets. These authors note that the spreads on investment-grade bonds are too low using ordinary parameter values, so they may have boosted volatility assumptions for a better fit in the investment-grade category. Unfortunately, this makes not only the speculativegrade spreads too high, but is more likely to involve a prediction of a downward-sloping credit yield curve.

\section{Conclusions}

Our evidence indicates that the term structure of credit risk facing high yield issuers usually has a positive slope. Most of the matched sets in the SDC data show a strict increase in the spread along the term structure. These differences are all statistically significant. The results based on secondary prices also point to an upward-sloping curve for risky bonds. Moreover, there is no indication that the downward-sloping curves are found among the riskier firms. 
Our results contradict previous evidence in Sarig and Warga (1989) and Fons (1994). The difference in our results appears to reflect the effects of credit quality variation among ratings categories. The safer high yield issuers in a given rating category tend to have longer term bonds, leading to a sample selection bias in regression estimates. We are able to overcome the lack of detail in the credit quality of ratings by looking at bonds of a particular firm that are in the same position in the capital structure.

What impact, if any, should this evidence have on bond pricing models? Researchers have a wide range of parameter values to choose from when calibrating their models, and until now, they may have intentionally been choosing values that result in downward-sloping credit yield curves for the riskiest firms. The value of the models would be more apparent if researchers instead chose parameters for leverage and firm risk that are in line with actual risk in the speculative-grade bond market. In other words, such credit curves may exist theoretically but are of little value if few actual issuers faces them. Leverage ratios that approach those of Merton's quasi-leverage ratios above one may not exist in the public bond market, and are certainly not typical of the high-yield bond market. Even models that use credit ratings directly, such as Jarrow, Lando, and Turnbull (1997), predict downward-sloping credit yield curves. These may also suffer from inappropriate assumptions about parameter values, such as incorporating an excessively high volatility of operating earnings to boost the spreads on high-grade bonds. 


\section{References}

Crabbe, Leland E., 1991, Callable corporate bonds: A vanishing breed, FEDS working paper \#155, Board of Governors of the Federal Reserve System.

Crabbe, Leland E., and Jean Helwege, 1994, Alternative tests of agency theories of callable corporate bonds," Financial Management 4, 3-20.

Duffee, Gregory R., forthcoming, The relationship between Treasury yields and corporate bond yield spreads, Journal of Finance.

Fabozzi, Frank J., 1994, Valuation of Fixed Income Securities (Fabozzi Associates, Summit, N.J.).

Fons, Jerome S., 1994, Using default rates to model the term structure of credit risk, Financial Analysts Journal 50, 25-32.

Jarrow, Robert A., David Lando, and Stuart M. Turnbull, 1997, A Markov model for the term structure of credit risk spreads, Review of Financial Studies 10, 481-522.

Longstaff, Francis A., and Eduardo S. Schwartz, 1995, A simple approach to valuing risky fixed and floating rate debt, Journal of Finance 50, 789-819.

Merton, Robert C., 1974, On the pricing of corporate debt: The risk structure of interest rates, Journal of Finance 29, 449-470.

Pitts, C. G. C., and M. J. P. Selby, 1983, The pricing of corporate debt: A further note, Journal of Finance 38, 1311-1313.

Ravid, S. Abraham, 1996, Debt maturity - A survey, Financial Markets, Institutions, and Instruments 5, no. 3, 1-69.

Sarig, Oded, and Arthur Warga, 1989, Some empirical estimates of the risk structure of interest rates, Journal of Finance 44,1351-1360.

Standard \& Poor's, 1995, Adjusted key industrial financial ratios, Creditweek, October 9, 49-55.

Warga, Arthur, 1995, Book review of "Valuation of Fixed Income Securities," Journal of Finance 50, 761-764.

Warga, Arthur, 1997, Lehman Brothers Fixed Income Database, documentation, at 
www.uh.edu/ awarga.

Wei, David Guoming and Dajiang Guo, 1997, Pricing risky debt: An empirical comparison of the Longstaff and Schwartz and Merton models, Journal of Fixed Income 7, 8-28. 
* The Federal Reserve Bank of New York and Blackrock Financial Management, Inc. We are grateful for helpful comments from Richard Cantor, Lea Carty, Ian Cooper, Lee Crabbe, Greg Duffee, Jerry Fons, Max Holmes, Brad Jordan, Tim Opler, Frank Packer, Stephen Vogt, Arthur Warga, and participants in seminars at the Federal Reserve Bank of New York, Rutgers Newark, the 1997 Financial Management Association meetings and the 1998 American Finance Association meetings. Phil de Imus, Paul Kleiman, Vhan Tran and Kin Cheng provided excellent research assistance. The views expressed in this paper are ours and do not necessarily reflect the position of the Federal Reserve Bank of New York or the Federal Reserve System.

1. See, for example, Warga's (1995) review of Fabozzi (1994).

2 . Wei and Guo (1997) find weak support, at best, for Merton's (1974) and Longstaff and Schwartz's (1995) models, for a variety of reasons in addition to the shape of the credit term structure. In a related paper, Duffee (forthcoming) shows that the negative correlation between Treasuries and corporate bond indices likely reflects call features more than it does the relationship between asset values and interest rates postulated in the Longstaff and Schwartz model.

3. The bonds in Fons' (1994) study are more likely to be called than those in our study of SDC bonds because call options are out of the money at issuance, whereas some outstanding bonds' options may be in the money. The bonds in Sarig and Warga's (1989) sample are less likely to be called than newly issued bonds because they are discount bonds with a first call price of 100 . Thus, the discount bonds would have to be close to maturity, to have risen sharply in credit quality or to have been issued during a period of much higher interest rates for the call option to be exercised.

4. That is, if we were to only use the first and last data points of a triplet, instead of the first to middle pair and middle to endpoint pair that we use, the results would be more supportive of an upward-sloping credit yield curve, because two-thirds of the beginning to end datapoints show a positive slope.

5. The fact that both Midlantic bonds were trading at the same price is evidence that Midlantic bonds were trading to the same de facto maturity 


\section{Table I}

\section{Creation of the Sample of Bonds - SDC Data}

The initial sample includes all speculative-grade bonds issued between 1977 and 1994. Spread data are provided by Securities Data Corporation (SDC). Cases can be larger than the number of firms because some firms contribute data more than one time to the sample.

Bonds Cases

(1) All straight public corporate bonds offered for sale in the U.S. between 1977 and 1994 that were not investment-grade

(2) All bonds in (1) that were sold on the same day as another bond of the same company

(3) All bonds in (2) that differ by maturity

(4) All bonds in (3) with rating information

(5) All bonds in (4) that have the same seniority as other bonds in the matched set

(6) All bonds in (5) with the same type of coupon as other bonds in the matched set

(7) All bonds in (6) with known spreads over comparable Treasuries 
Table II

The Speculative-Grade Credit Yield Curve

The sample includes all matched sets of speculative-grade bonds issued between 1977 and 1994. A matched set of bonds is comprised of all bonds issued on the same day by the same firm that all have the same characteristics except maturity and yield and call features. A matched set contributes $n-1$ pairs to the sample, where $n$ is the number of bonds issued. Outcomes are the sign of the change in the spread as maturity increases for bonds in the set. "All cases" results are based on all bonds in the matched set, whereas "All bonds noncall life" are based on the bonds in the matched set that are noncallable for life, and "All bonds callable" are results based on only the callable bonds in the matched set. Bond spreads are calculated over the nearest on-the-run Treasury and are provided by Securities Data Corporation. BB-rated bonds are those whose highest rating from Moody's Investors Service or Standard \& Poor's is Ba3 or higher or BB- or higher, respectively.

\begin{tabular}{|c|c|c|c|c|c|}
\hline \multirow[b]{2}{*}{ Outcomes: } & \multicolumn{3}{|c|}{$\mathrm{BB}$} & \multicolumn{2}{|c|}{$\mathrm{B}$} \\
\hline & All cases & $\begin{array}{c}\text { All bonds } \\
\text { noncall life }\end{array}$ & $\begin{array}{l}\text { All bonds } \\
\text { callable }\end{array}$ & All cases & $\begin{array}{l}\text { All bonds } \\
\text { callable }\end{array}$ \\
\hline Up & 22 & 14 & 12 & 16 & 13 \\
\hline Down or flat & 5 & 5 & 1 & 1 & 1 \\
\hline Up, Up & 9 & 0 & 1 & 1 & 1 \\
\hline Down, Down & 0 & 0 & 0 & 0 & 0 \\
\hline Up, Down & 3 & 2 & 0 & 3 & 2 \\
\hline Down, Up & 1 & 0 & 0 & 0 & 0 \\
\hline Up, Up, Up & 0 & 0 & 0 & 1 & 1 \\
\hline Up, Up, Down & 1 & 1 & 0 & 0 & 0 \\
\hline Down, Up, Down & 1 & 1 & 0 & 0 & 0 \\
\hline Percent All Up & $74 \%$ & $61 \%$ & $93 \%$ & $82 \%$ & $83 \%$ \\
\hline Total \# of Cases & 42 & 23 & 14 & 22 & 18 \\
\hline Total \# of Bonds & 110 & 54 & 36 & 53 & 43 \\
\hline
\end{tabular}




\section{Table III \\ Matched-Pair Statistical Tests of the Slope of the Speculative-Grade Credit Yield Curve - SDC Data}

Bonds issued on the same day by the same firm that all have the same characteristics except maturity and yield constitute a matched set. A matched set contributes $n$ 1 pairs to the sample, where $\mathrm{n}$ is the number of bonds issued. "All cases" results are based on all bonds in the matched set, whereas "All bonds noncall life" are based on the bonds in the matched set that are noncallable for life, and "All bonds callable" are results based on only the callable bonds in the matched set. Bond spreads are calculated over the nearest on-the-run Treasury bond and are provided by Securities Data Corporation (SDC). The sample includes matched sets of speculative-grade bonds issued during 1977-1994. BB-rated bonds are those whose highest rating from Moody's Investors Service or Standard \& Poor's is Ba3 or higher or BB- or higher, respectively. ${ }^{* * *}$ denotes statistically significant at the 1 percent level

\begin{tabular}{|c|c|c|c|c|c|}
\hline & \multicolumn{3}{|c|}{$\mathrm{BB}$} & \multicolumn{2}{|r|}{$\mathrm{B}$} \\
\hline & All cases & $\begin{array}{l}\text { All bonds } \\
\text { noncall life }\end{array}$ & $\begin{array}{l}\text { All bonds } \\
\text { callable }\end{array}$ & All cases & $\begin{array}{l}\text { All bonds } \\
\text { callable }\end{array}$ \\
\hline $\begin{array}{l}\text { Mean difference in spread } \\
\text { over comparable } \\
\text { Treasury (basis points) }\end{array}$ & 21 & 14 & 33 & 19 & 18 \\
\hline $\begin{array}{l}t \text {-statistic for mean } \\
\text { difference in spread } \\
\text { equal to zero }\end{array}$ & $5.47^{\star \star \star}$ & $2.82^{\star \star \star}$ & $3.84^{\star \star *}$ & $3.99^{* \star *}$ & $3.86^{\star \star \star}$ \\
\hline Number of matched pairs & 59 & 29 & 15 & 28 & 23 \\
\hline $\begin{array}{l}\text { Wilcoxon signed rank test for } \\
\text { pairs having equal spreads }\end{array}$ & $z=4.76^{\star \star \star}$ & $z=2.45$ & $\mathrm{~T}+=14^{\star * *}$ & $z=3.40^{\star * *}$ & $z=3.19^{* * *}$ \\
\hline $\begin{array}{l}\text { Number of matches with } \\
\text { unequal spreads }\end{array}$ & 58 & 29 & 14 & 28 & 23 \\
\hline $\begin{array}{l}\text { Mean difference in maturity of } \\
\text { bonds in pair (years) }\end{array}$ & 7 & 6 & 9 & 4 & 4 \\
\hline
\end{tabular}




\section{Table IV}

\section{Regression Estimates of the Credit Yield Curve}

Panel A presents regression coefficients for all high yield bonds issued during 1979-1994 in the Securities Data Corporation (SDC) database, where the regression runs the spead over the nearest on-the-run Treasury on the maturity of the bond. Panels $\mathrm{B}$ and $\mathrm{C}$ show estimates from the same regression model using only the bonds in the sample of matched sets. t-statistics are in parentheses and ${ }^{* \star *},{ }^{* *},{ }^{*}$ indicate significance at the $0.01,0.05$, and 0.1 levels, respectively.

Panel A. All Newly Issued Bonds in SDC Database 1979-1994

\begin{tabular}{lcccc} 
& Constant & Maturity & $\mathrm{n}$ & $\mathrm{R}^{2}$ \\
\hline B-rated or lower & $505.1(42.4)^{*+*}$ & $-3.42(-3.28)^{* * *}$ & 888 & 0.01 \\
$\quad$ Maturity 20 years or less & $500.0(35.8)^{*+*}$ & $-2.88(-2.23)^{* *}$ & 853 & 0.01 \\
BB-rated or higher & $330.9(32.1)^{*+*}$ & $-1.69(-2.09)^{* *}$ & 586 & 0.01 \\
$\quad$ Maturity 20 years or less & $287.3(18.1)^{*+*}$ & $3.12(1.99)^{* *}$ & 518 & 0.01
\end{tabular}


Table IV (continued)

Regression Estimates of the Credit Yield Curve

Panel B. Matched Bonds Pooled - Whole Letter Ratings

\begin{tabular}{lcccc} 
& Constant & Maturity & $\mathrm{n}$ & $\mathrm{R}^{2}$ \\
\hline B-rated or lower & $492.2(14.1)^{*+*}$ & $-3.93(-1.20)$ & 53 & 0.03 \\
$\quad$ Maturity 20 years or less & $536.0(11.6)^{*+*}$ & $-9.29(-1.88)^{*}$ & 51 & 0.07 \\
BB-rated or higher & $310.5(15.6)^{*+*}$ & $-1.52(-1.18)$ & 110 & 0.01 \\
$\quad$ Maturity 20 years or less & $295.2(10.8)^{*+*}$ & $0.31(0.13)$ & 88 & 0.00
\end{tabular}

Panel C. Matched Bonds Pooled - Modified Ratings

\begin{tabular}{|c|c|c|c|c|}
\hline & Constant & Maturity & $\mathrm{n}$ & $\mathrm{R}^{2}$ \\
\hline $\mathrm{B}, \mathrm{B}$ - or lower & $596.80(8.8)^{* \star *}$ & $-9.70(-1.36)$ & 25 & 0.07 \\
\hline Maturity 20 years or less & - & - & 25 & - \\
\hline B+ bonds & $388.9(8.6)^{* \star *}$ & $1.35 \quad(0.82)$ & 28 & 0.03 \\
\hline Maturity 20 years or less & $451.6(13.7)^{\star \star *}$ & $-5.98 \quad(-1.67)$ & 26 & 0.10 \\
\hline BB, BB- bonds & $368.9(8.6)^{* \star *}$ & $-0.18 \quad(-0.05)$ & 28 & 0.00 \\
\hline Maturity 20 years or less & $348.7(6.6)^{* * *}$ & $2.08 \quad(0.46)$ & 26 & 0.01 \\
\hline Highest rating is $\mathrm{BB}+$ & $385.8(12.8)^{* \star *}$ & $-5.28(-2.73)^{* *}$ & 32 & 0.20 \\
\hline Maturity 20 years or less & $389.3(9.0)^{* \star *}$ & $-5.70(-1.49)$ & 26 & 0.08 \\
\hline BB+/BBB- bonds & $188.5(10.3)^{* \star *}$ & $2.95(2.62)^{* *}$ & 50 & 0.13 \\
\hline Maturity 20 years or less & $178.7(7.7)^{* \star *}$ & $4.10(2.08)^{*}$ & 36 & 0.11 \\
\hline
\end{tabular}


Table V

The Speculative-Grade Credit Yield Curve Based on Matched Bonds

Secondary Price Data - Month with Most Trades of B-rated Bonds

Outcomes are the sign of the change in the spread as maturity increases for bonds in the Lehman Brothers Fixed Income Database. B bonds are those with a Moody's rating not higher than B1 or a S\&P rating not higher than $\mathrm{B}+$; all other bonds in the sample of speculative-grade bonds have at least one rating equivalent to BB- or higher.

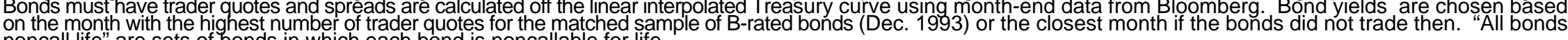
noncall life" are sets of bonds in which each bond is noncallable for life.

\begin{tabular}{lc|c}
\hline & BB & B \\
\cline { 2 - 3 } Outcomes: & All bonds noncall life & All bonds noncall life \\
\cline { 2 - 3 } Up & 12 & 4 \\
Down & 1 & 1 \\
Up, Up & 2 & 1 \\
Up, Down & 2 & 0 \\
Down, Up & 0 & 0 \\
Up, Up, Up & 4 & 1 \\
Up, Up, Down & 1 & 0 \\
Down, Down, Up & 1 & 1 \\
Up, Down, Up & 1 & 0 \\
Down, Up, Down & 3 & \\
Five or more bonds: & 38 & \\
Mostly Up & $31 \%$ & $75 \%$ \\
Percent All or Mostly Up & 306 & \\
Total \# of Cases & & \\
Total \# of Bonds & &
\end{tabular}


Table VI

Matched-Pair Statistical Tests of the Slope of

the Speculative-Grade Credit Yield Curve - Secondary Bond Prices

The tests are calculated using spreads from bonds in the Lehman Brothers Fixed Income Database that are alike in all characteristics except maturity (e.g., same issuer, same seniority). B bonds are those with a Moody's rating not higher than B1 or a S\&P rating not higher than B+; all other bonds in the sample of speculative-grade bonds have at least one rating eguivalent to BB- or higher. Bonds must have trader quotes and spreads are calculated off the linear interpolated Treasury curve using month-end

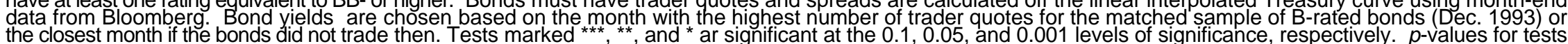
of significance of mean and median spreads are shown in parentheses. "All bonds noncall life" are sets of bonds in which each bond is noncallable for life.

\begin{tabular}{|c|c|c|}
\hline & $\mathrm{BB}$ & $\mathrm{B}$ \\
\hline & $\begin{array}{l}\text { All bonds } \\
\text { noncall life }\end{array}$ & $\begin{array}{c}\text { All bonds } \\
\text { noncall life }\end{array}$ \\
\hline $\begin{array}{l}\text { Mean difference in } \\
\text { spread over comparable } \\
\text { Treasury (basis points) }\end{array}$ & $37(0.98)$ & $2(0.97)$ \\
\hline $\begin{array}{l}\text { Median difference in } \\
\text { spread over comparable } \\
\text { Treasury (basis points) }\end{array}$ & $14(0.07)^{*}$ & $14(0.29)$ \\
\hline Number of matched pairs & 38 & 8 \\
\hline $\begin{array}{l}\text { Signed rank test for } \\
\text { pairs having equal } \\
\text { spreads }\end{array}$ & $z=2.14^{* *}$ & $\mathrm{~T}+=24$ \\
\hline $\begin{array}{l}\text { Mean difference in } \\
\text { maturity of bonds in pair } \\
\text { (years) }\end{array}$ & 10.2 & 7.6 \\
\hline
\end{tabular}


Table VII

Multiple Observations of Same Bond in Fixed Income Database

Results are based on all trader quotes of bonds in the matched samples of the Lehman Brothers Fixed Income Database during the period January 1991 - March 1995 Bonds can be included in the dataset as often as 51 times or as little as once (the bond trades during only one month). The slope of the credit yield curve, which is classified as either positive or negative, is measured by the difference in spreads over the interpolated Treasury curve of the longest and shortest maturity bonds of the matched set. Panel A shows results by major rating category, without regard to time period. Panel B shows slopes of the credit yield curve according to the steepness of the Treasury yield curve. The steepness of the Treasury curve is measured by the difference between the 10- and 2-year securities, which is always a positive number during this period. in the steepest Treasury curve quartile are shown in the row labeled "steep quartile" and all other bonds are included in the row labeled "middle, quartiles"

Panel A. Slopes of credit yield curves by rating

\begin{tabular}{lcc} 
Rating & Positive & Negative \\
\hline BB & 402 & 168 \\
B & 90 & 55 \\
\hline Total & 492 & 223
\end{tabular}

Panel B. Slopes of credit yield curves according to slope of Treasury yield curve

\begin{tabular}{lcc} 
Slope of Treasury curve & Positive & Negative \\
\hline Flattest quartile & 156 & 30 \\
Middle quartiles & 252 & 93 \\
Steep quartile & 84 & 100 \\
\hline Total & 492 & 223
\end{tabular}

